\title{
Environmental impacts of urbanization processes on the examples of Kecskemét and Győr Functional Urban Areas
}

\author{
Edit HOYK ${ }^{1}$ - Jenő Zsolt FARKAS ${ }^{2}$ - Tamás HARDI ${ }^{3}$ \\ 1: HAS Centre for Economic and Regional Studies, Institute for Regional Studies. Kecskemét, Rákóczi út. 3. \\ 6000; E-mail: hoyk.edit@krtk.mta.hu \\ 2: HAS Centre for Economic and Regional Studies, Institute for Regional Studies. Kecskemét, Rákóczi út. 3. \\ 6000; E-mail: farkasj@rkk.hu \\ 3: HAS Centre for Economic and Regional Studies, Institute for Regional Studies. Győr, Liszt Ferenc u. 10. \\ 9022; E-mail: hardit@rkk.hu
}

Keywords: environmental transformation; urban sprawl; suburbs; climate change

\section{Introduction}

The rapid development of suburbs and the urban sprawl were decisive phenomena in the urbanization process (Gardi, 2017; Szirmai, et al. 2011), which has many economic, social and environmental impacts in the last decades (Kovács, 2014; Kahn, 2000). Our research focuses on the environmental-ecological aspects of the changes, mainly because it is relatively less explored but with important lessons and consequences. While the main motivations to move out of cities are nature connectedness and to have a better quality of life, ultimately it leads to negative environmental impacts because the growth of built-up areas, decrease in natural plant cover and the arise of landscape aesthetic problems (Antrop, 2004). Outmigration to suburbs causes intensive road traffic, which leads to bigger air pollution and fossil energy use. In our study, we highlight some of these environmental changes and outcomes through the examples of Kecskemét and Györ, which are characterized by rapid industrial development nowadays.

\section{Materials and methods}

We analysed the suburban zones around Györ and Kecskemét with land use and land cover data of CORINE Land Cover and Urban Atlas. According to the Urban Atlas, the agglomeration of Kecskemét consists of 23, while in case of Györ 68 settlements. The land cover datasets were used to identify the phenomenon of urban sprawl, which is a morphological based concept. Beside land use and land cover examinations we also analysed population growth, migration and road traffic data to evaluate the suburbanisation process in the FUA's of the two cities. The population and migration data were downloaded from the Regional Development and Spatial Planning Information System (TEIR), which consists the datasets of the Hungarian Central Statistical Office (KSH). The traffic data based on traffic calculations of the Hungarian Roads Non-profit Ltd. 2008 - 2017.

\section{Results and discussion}

Three settlement groups can be identified in the selected FUA's. The first one consists of settlements (some of them within the administrative boundary of the centre), which are very close or grown into the central city. They have rapidly growing populations because of the intensive outmigration from the centre and immigration from other areas. The second settlement group is a little bit further from the centre, and also affected by immigration. The third group of settlements inside the FUA's has the least inhabitants and probably characterized by a decline in population. There is a significant difference 
between the two cases. Kecskemét is a classical example of suburbanisation, where the settlements closer to the centre have a relatively significant extra population on an annual basis, because of the outmigration from the centre. In case of Györ, the population growth mainly comes from immigration from other regions of Hungary, which led to a continuous expansion of the centre's built up area. These were semi-natural or agricultural lands earlier. Focusing on road traffic intensity changes, the study areas show many similarities. The two agglomerations are growing faster along new roads, and in parallel the traffic growth is already significant, and predictably will be more dynamic in the future. The land conversion data from Corine CLC and UA shows the same fundamental changes in the study areas, which mean an increase of artificial surfaces and in parallel a decrease in agricultural lands. It has to be noted, that the annual growth rate of built-up surfaces decreased in Györ after mid 2000's, while it has increased in Kecskemét. This shows the delayed industrial development of Kecskemét and generally the south-eastern region of Hungary.

\section{Conclusions}

The processes of urban sprawl and suburbanisation are major factors in the environmental changes of the selected cities and their FUA's in the last decades. We can conclude that the examined processes affect mainly the settlements near to the centre, or in many cases they are within the administrative boundaries of the cities. The consequences are wide-spread from the decline of green surfaces to the negative micro-climatic changes. The effects go beyond the environment and bring significant changes to both the economy and to the everyday life of local societies in various forms, such as more intensive and spatially expanding urban heat islands or increasing number of heat waves. In order to mitigate the above mentioned negative trends, it would be desirable to handle more consciously the processes of urban sprawl and suburbanisation in the future.

\section{Acknowledgement}

This research was support by the National Research, Development and Innovation Fund (NKFIA). Reference number: NKFI-6-K-128703

\section{References}

Antrop, M. (2004): Landscape change ant the urbanization process in Europe. Landscape and Urban Planning, Vol. 67., pp. 9-26. DOI: https://doi.org/10.1016/S0169-2046(03)00026-4

Gardi, C. (2017): Is urban expansion a problem? In: Gardi, C. (ed.): Urban expansion, land cover and soil ecosystem services. Routledge, London and New York, pp. 1-18. DOI: https://doi.org/10.4324/9781315715674-1

Kahn, M.E. (2000): Environmental impact of suburbanization. Journal of Policy Analysis and Management, Vol. 19., No. 4., pp. 569-586. DOI: https://doi.org/10.1002/1520-6688(200023)19:4<569::aid-pam3>3.0.co;2-p

Kovács, Z. (2014): New post-socialist urban landscapes: The emergence of gated communities in East Central Europe. Cities, Vol. 36., pp. 179-181. DOI: https://doi.org/10.1016/j.cities.2013.09.001

Szirmai, V. (2012): Urban sprawl in Europe. Regional Statistics, Vol. 2., pp. 129-148. DOI: https://doi. org/10.15196/rs02109 